Research paper

\title{
Suicide by hanging is a priority for suicide prevention: method specific suicide in India (2001-2014)
}

\author{
Vikas Arya $^{\mathrm{a}, *}$, Andrew Page ${ }^{\mathrm{a}}$, David Gunnell ${ }^{\mathrm{b}}$, Rakhi Dandona ${ }^{\mathrm{c}, \mathrm{d}}$, Haider Mannan ${ }^{\mathrm{a}}$, \\ Michael Eddleston ${ }^{\mathrm{e}}$, Gregory Armstrong ${ }^{\mathrm{f}}$ \\ ${ }^{a}$ Translational Health Research Institute, Western Sydney University, Australia \\ ${ }^{\mathrm{b}}$ Population Health Sciences, Bristol Medical School, University of Bristol, UK \\ ${ }^{\mathrm{c}}$ Public Health Foundation of India, Gurugram, India \\ ${ }^{\mathrm{d}}$ Institute for Health Metrics and Evaluation, University of Washington, Seattle, USA \\ ${ }^{\mathrm{e}}$ Centre for Pesticide Suicide Prevention, and Pharmacology, Toxicology, \& Therapeutics, University/BHF Centre for Cardiovascular Science, University of Edinburgh, \\ Edinburgh, UK \\ ${ }_{\mathrm{f}}^{\mathrm{f}}$ Nossal Institute for Global Health, Melbourne School of Population and Global Health, The University of Melbourne, Australia
}

\section{A R T I C L E I N F O}

\section{Keywords:}

\section{Suicide}

\section{Hanging}

Insecticide poisoning

Pesticide poisoning

India

\begin{abstract}
A B S T R A C T
Background: India accounts for over a quarter of the global burden of suicide. One of the most effective population level suicide prevention strategies has been restricting access to suicide means.

Method: Trends in method specific suicide rates (2001-14) were calculated using National Crime Records Bureau data stratified by sex, age-group, and geographical region. Multilevel negative binomial regression models stratified by sex and suicide method were specified to investigate associations between state-level indicators of economic development, education, agricultural pesticide use and religious factors.

Results: Suicide by hanging increased by $56 \%$ (from 3.9 to 6.1 per 100,000) among males and by $24 \%$ (from 2.1 to 2.6 per 100,000) among females over the study period while incidence of insecticide poisoning decreased by $44 \%$ (from 2.7 to 1.5 per 100,000) among males and by $52 \%$ (from 1.7 to 0.8 per 100,000) among females. In general, states with higher levels of development, higher agricultural employment and higher literacy had higher rates of suicide for each suicide method. States with higher levels of agricultural pesticide use had higher rates of insecticide poisoning suicides.

Limitation: Reported rates might be an underestimation of the true rates as the official data used for the analysis likely underestimates the actual number of suicide deaths in India.

Conclusion: Responsible reporting of suicide by hanging in the media, and limiting fictional portrayals of this method may be useful areas for prevention. Further restrictions on production and sales of highly hazardous pesticides may also help with further reductions in suicide by pesticide poisoning.
\end{abstract}

\section{Introduction}

Suicide is a major public health issue in India (Patel et al., 2012; Dandona et al., 2016; Armstrong and Vijayakumar, 2018; Arya et al., 2018) with an estimated 230,314 suicides in 2016 (Dandona et al., 2018). India accounts for over a quarter of the global burden of suicide (Dandona et al., 2018). Rates in India are higher among males (21 per $100,000)$ than females (15 per 100,000), and while rates have declined among females, male rates have remained stable for the last 30 years (Dandona et al., 2018). Given the enormous size of the problem, a public health approach to suicide is gaining momentum in India, with calls for the development of national and state-level suicide prevention strategies (Armstrong and Vijayakumar 2018; Dandona et al., 2018). To give further impetus to the development of such strategies and targeted suicide prevention activities, information is urgently needed on trends and regional variation in suicide methods.

The changing availability of lethal suicide methods is an important influence on secular trends and international differences in suicide rates (WHO, 2014), and restricting access to means is recognised as one of the most effective population level suicide prevention strategies to date (Mann et al., 2005). Reduction in both method-specific, and in some cases overall, suicide rates have been reported following the restriction of access to carbon monoxide in domestic gas (Kreitman, 1976) and in motor vehicles following the introduction of catalytic converters

\footnotetext{
* Corresponding author.

E-mail address: v.arya@westernsydney.edu.au (V. Arya).
} 
(Spittal et al., 2012); barbiturate availability (Oliver and Hetzel, 1972); agricultural pesticides (Gunnell et al., 2007) and firearms (Beautrais et al., 2006). Means restriction is most effective when the method is lethal and commonly available, and if substitution of method does occur, it is to a method of lower lethality increasing the chances of survival (Yip et al., 2012; Chen et al., 2016).

Few studies have investigated national and state level trends in method specific suicide rates in India (Patel et al., 2012; Dandona et al., 2016), although a number of studies have reported method-specific suicides for specific geographic catchments. For example, a study from west India found poisoning as the leading method of suicide (Ambade et al., 2007) while another study in south India found hanging as the leading method of suicide (Sauvaget et al., 2009). This study uses national data on method specific suicides in India for the period 2001-14 to: (i) identify national and regional patterns in method-specific suicide rates; and (ii) investigate potential social, demographic and economic correlates of state-level variation in suicide methods in India.

\section{Method}

\subsection{Data}

The National Crime Records Bureau (NCRB) is the Indian government organization that reports crime data based on police reports collected from each state and union territory in India. Method specific suicide counts for the period 2001-14 were extracted from the National Crime Records Bureau (NCRB) website, stratified by sex, year, state and age-group (15-29 years, 30-44 years, 45-60 years and $>=60$ years). The NCRB defines suicide as the deliberate termination of life where the desire to terminate life originates within the individual (NCRB, 2014).

The data provided by the NCRB for 2001-2013 defined age groups as described above. However, in 2014 NCRB reported the additional groups of 14-18 years and 18-29 years, which were aggregated to form a single age group of 14-29 years for 2014 for this analysis. Additionally, in 2014 the state of Andhra Pradesh was split to form two states: Andhra Pradesh and Telangana. Suicide cases from Telangana and Andhra Pradesh were combined for 2014 to ensure consistency with previous years in the analysis. The latest NCRB data from 2015 was not included because it does not provide method specific suicide counts by different age groups. Data on corresponding populations stratified by sex, year, state and age-group were extracted from Census of India website for 2001 (Census of India, 2001) and 2011 (Census of India, 2011) with intercensal years calculated via weighted interpolation.

The NCRB data recorded 16 categories of suicide method (Web Appendix 1). Following initial analysis, the current study reported on the three most common suicide methods (accounting for $58 \%$ of the total suicides in males and $63 \%$ in females): 'hanging', 'insecticide poisoning' (this category includes all suicides due to any form of pesticide) and 'self-immolation'. The remaining suicide methods were categorised as 'all other methods'.

A series of social and economic factors were also defined including state specific information on literacy, religion, agricultural pesticide use, level of socio-economic development and level of agricultural employment (Vijayakumar et al., 2005; Dandona et al., 2016; Page et al., 2017; Arya et al., 2018). Data on state specific literacy and religious affiliation rates were obtained from the Census of India and Open Government Data Platform of India websites (Literates and Literacy Rates by Sex, 2018; Population by Major Religious Communities; Religion Census, 2011). These rates were available for the years 2001 and 2011 with intervening years estimated via weighted interpolation. State-specific agricultural pesticide use rates (based on total production and imports of different pesticides) between the years 2002-13 (with 2001 and 2014 rates estimated via retrospective projection) were obtained from the Indian Agricultural Statistics Research Institute (IASRI) (IASRI, 2013, 2016).
Indian states were categorised in terms of socio- economic development ('less' or 'more' developed) and also level of agricultural employment ('more' or 'less' agricultural). A detailed description of the rationale and method for these categorisations has been published elsewhere (Dandona et al., 2016; Arya et al., 2018) (see Web Appendix 2).

\subsection{Analysis}

Age-standardised rates (using the 2011 census population as the standard) for suicide by hanging, insecticide poisoning, self-immolation and all other methods were calculated for each year (2001-2014), stratified by sex and geographic region (less or more economically developed, and more or less agriculturally employed), to investigate trends and differentials over the study period. Age-specific rates stratified by sex were also investigated to ascertain differences in methodspecific suicide rates among different age groups. Age standardised suicide rates for males and females for hanging, insecticide poisoning, self-immolation and all other methods for each state were also calculated (Web Appendix 3-6). Total percentage of hanging, insecticide poisoning, self-immolation and all other methods from 2001-2014 were calculated as well.

Associations between socio-demographic factors (literacy, religion, agricultural pesticide use and geographic region) and suicide were investigated by specifying a series of negative binomial regression models of method specific suicide counts (offset by the natural logarithm of the population), and stratified by state, sex, geographic region, and age group. Each of the socio-demographic factors were divided into population tertiles for analyses, resulting in 'low', 'middle' and 'high' categories for each variable. Religion was restricted to proportion Hindu, as high collinearity was observed between proportion Muslim, Christian and Hindu by state. Multivariate models were adjusted for sex, agegroup, period, and socio-demographic factors (literacy, religion, agricultural pesticide use, geographic region). Model estimates were exponentiated and expressed as rate ratios (RR) with 95\% confidence intervals. Analyses were conducted in Stata 15.1 (Mitchell, 2012).

\section{Results}

Suicide by hanging showed a general increasing trend with sharp increases during the latter years of the study period (2010-2014), occurring contemporaneously with declines in suicide by insecticide poisoning (Table 1, Fig. 1). Among males, suicide by hanging increased by $56 \%$ (from 3.9 to 6.1 per 100,000 ) while suicide by insecticide poisoning decreased by $44 \%$ (from 2.7 to 1.5 per 100,000 ) between 2001 and 2014. Suicide by self-immolation decreased by $14 \%(0.7-0.6$ per 10,000) and all other methods also decreased by 3\% (5.9-5.7 per 100,000) (Fig. 1a). Among females, suicide by hanging also increased by $23 \%$ (from 2.1 to 2.6 per 100,000 ) while insecticide poisoning declined by $52 \%$ (from 1.7 to 0.8 per 100,000) between 2001 and 2014 . Suicide by self-immolation decreased by $40 \%$ (from 1.5 to 0.9 per $100,000)$ while all other methods also decreased by $20 \%$ (3.5-2.8 per 100,000) (Fig. 1a).

Among males, middle age groups (30-59 years) had the highest suicide rates for all methods (Fig. 1b). Among females, suicide rates generally declined with age among the three specific suicide methods, especially for hanging (Fig. 1b).

More economically developed states had two to four times higher suicide rates for all the methods compared to less economically developed states among both sexes (Fig. 2a and b), with a general pattern of increasing suicide by hanging, and declines in suicide by insecticide poisoning. Among more or less agricultural states, there was a similar pattern of suicide methods, with slightly higher rates of suicide by hanging among males in less agricultural states, and suicide by selfimmolation among females in more agricultural states (Fig. 3a and b).

More agricultural states also had slightly higher rates of insecticide 
Table 1

Percentage of hanging, insecticide poisoning, self-immolation and all other methods among males and females from 2001-14.

\begin{tabular}{|c|c|c|c|c|c|c|c|c|c|c|c|c|c|c|c|}
\hline & 2001 & 2002 & 2003 & 2004 & 2005 & 2006 & 2007 & 2008 & 2009 & 2010 & 2011 & 2012 & 2013 & 2014 & Total \\
\hline \multicolumn{16}{|l|}{ Males } \\
\hline Hanging $\%$ & $29.65 \%$ & $30.68 \%$ & $31.28 \%$ & $33.06 \%$ & $34.00 \%$ & $33.83 \%$ & $33.43 \%$ & $33.90 \%$ & $33.23 \%$ & $33.25 \%$ & $34.91 \%$ & $39.15 \%$ & $41.93 \%$ & $44.21 \%$ & $35.07 \%$ \\
\hline Cases & 19,668 & 21,276 & 21,966 & 24,020 & 24,786 & 25,610 & 26,509 & 27,332 & 27,079 & 28,988 & 30,667 & 34,631 & 37,969 & 39,410 & 389,911 \\
\hline Insecticide poisoning $\%$ & $20.33 \%$ & $19.78 \%$ & $21.56 \%$ & $20.93 \%$ & $19.90 \%$ & $20.34 \%$ & $20.02 \%$ & $19.55 \%$ & $21.08 \%$ & $19.29 \%$ & $16.52 \%$ & $14.87 \%$ & $14.31 \%$ & $11.00 \%$ & $18.31 \%$ \\
\hline Cases & 13,487 & 13,716 & 15,145 & 15,210 & 14,516 & 15,398 & 15,876 & 15,766 & 17,176 & 16,822 & 14,512 & 13,161 & 12,962 & 9806 & 203,553 \\
\hline Self-immolation $\%$ & $5.28 \%$ & $5.13 \%$ & $5.07 \%$ & $3.85 \%$ & $3.94 \%$ & $4.53 \%$ & $4.35 \%$ & $4.94 \%$ & $4.85 \%$ & $4.74 \%$ & $4.87 \%$ & $4.64 \%$ & $4.05 \%$ & $3.97 \%$ & $4.57 \%$ \\
\hline Cases & 3507 & 3560 & 3567 & 2804 & 2874 & 3434 & 3452 & 3982 & 3959 & 4137 & 4279 & 4112 & 3672 & 3545 & 50,884 \\
\hline All other methods \% & $44.71 \%$ & $44.39 \%$ & $42.07 \%$ & $42.14 \%$ & $42.15 \%$ & $41.29 \%$ & $42.19 \%$ & $41.59 \%$ & $40.82 \%$ & $42.70 \%$ & $43.69 \%$ & $41.32 \%$ & $39.69 \%$ & $40.80 \%$ & $42.03 \%$ \\
\hline Cases & 29,652 & 30,780 & 29,543 & 30,617 & 30,740 & 31,260 & 33,458 & 33,464 & 33,257 & 37,233 & 38,381 & 36,549 & 35,940 & 36,376 & 467,250 \\
\hline \multicolumn{16}{|l|}{ Females } \\
\hline Hanging $\%$ & $23.91 \%$ & $24.60 \%$ & $26.10 \%$ & $27.96 \%$ & $28.71 \%$ & $30.87 \%$ & $28.49 \%$ & $29.08 \%$ & $28.29 \%$ & $28.01 \%$ & $30.05 \%$ & $32.83 \%$ & $35.40 \%$ & $36.75 \%$ & $29.42 \%$ \\
\hline Cases & 10,089 & 10,109 & 10,605 & 11,479 & 11,773 & 13,096 & 12,352 & 12,936 & 12,927 & 13,278 & 14,348 & 15,431 & 15,667 & 15,631 & 179,721 \\
\hline Insecticide poisoning\% & $19.06 \%$ & $18.73 \%$ & $19.33 \%$ & $19.73 \%$ & $19.02 \%$ & $17.80 \%$ & $19.03 \%$ & $18.27 \%$ & $19.18 \%$ & $17.85 \%$ & $15.27 \%$ & $14.43 \%$ & $14.40 \%$ & $10.66 \%$ & $17.31 \%$ \\
\hline Cases & 8043 & 7698 & 7856 & 8101 & 7800 & 7549 & 8249 & 8129 & 8765 & 8466 & 7292 & 6768 & 6496 & 4535 & 105,747 \\
\hline Self-immolation \% & $17.33 \%$ & $17.26 \%$ & $16.80 \%$ & $14.35 \%$ & $14.88 \%$ & $16.05 \%$ & $16.01 \%$ & $15.74 \%$ & $16.83 \%$ & $16.33 \%$ & $15.89 \%$ & $15.42 \%$ & $15.58 \%$ & $13.11 \%$ & $15.74 \%$ \\
\hline Cases & 7315 & 7095 & 6828 & 5893 & 6104 & 6809 & 6939 & 7004 & 7691 & 7748 & 7587 & 7326 & 6292 & 5576 & 96,207 \\
\hline All other methods \% & $39.68 \%$ & $39.38 \%$ & $37.75 \%$ & $37.94 \%$ & $37.37 \%$ & $35.26 \%$ & $36.45 \%$ & $36.88 \%$ & $35.67 \%$ & $37.80 \%$ & $38.78 \%$ & $37.24 \%$ & $37.17 \%$ & $39.47 \%$ & $37.51 \%$ \\
\hline Cases & 16,745 & 16,183 & 15,341 & 15,573 & 15,321 & 14,956 & 15,802 & 16,404 & 16,297 & 17,927 & 18,519 & 17,467 & 15,801 & 16,787 & 229,123 \\
\hline
\end{tabular}

poisoning among both sexes (Fig. 3a and b).

States with higher (compared to low) literacy had a higher risk of suicide by hanging, insecticide poisoning, and self-immolation (RR range 2.08-6.41) (Table 2). There was also a strong association (RRs $>2.0$ ) between higher (compared to low) per capita agricultural pesticide use, and among more (compared to less) agricultural regions, and suicide by insecticide poisoning, for males and females (Table 2). Less developed states had lower rates of suicide for all suicide methods (with the exception of female suicide by hanging). States with high (compared to low) proportion Hindu populations had higher rates of suicide by insecticide poisoning and self-immolation, for both males and females (Table 2).

\section{Discussion}

This study investigated trends and differentials in method-specific suicide in India over the period 2001-14. Suicide by hanging was the most common method in India, followed by suicide by insecticides, and suicide by self-immolation. Suicide by hanging accounted for $35 \%$ of all suicides among males and almost $30 \%$ of all suicides among females, with rates generally increasing over the study period. In contrast, suicide by insecticide poisoning (accounting for $18 \%$ of all suicides in males and $17 \%$ of all suicides in females) showed a decreasing trend over the study period. Self-immolation rates were higher among females compared to males (accounting for 5\% of all suicides among males, but $16 \%$ of all suicides among females) and also showed decreasing trends over the study period.

The current study found higher method-specific suicides among males compared to females (with the exception for suicide by self-immolation), which is consistent with sex differences reported internationally (WHO, 2011). Age specific suicide rates for all methods were generally higher in the middle age groups (30-44 and 45-59 years) among males, while suicide by hanging, insecticide poisoning and selfimmolation were highest among the youngest age group (15-29 years) among females. These findings are reflective of age-specific patterns of suicide in previously reported studies of overall suicide rates in India (Patel et al., 2012; Arya et al., 2018; Dandona et al., 2018).

Suicide by hanging is one of most common and lethal methods of suicide in the world (Gunnell et al., 2005; Ajdacic-Gross et al., 2008). Suicide by hanging has historically been a prominent method of suicide in India (Thakur, 1963), with capital punishment in India carried out through hanging, highlighting the prominence of hanging in the Indian culture. The increasing trend in suicide by hanging, occurring contemporaneously with declines in suicide by insecticide poisoning (and with no substantial changes among other methods, and consistent overall suicide rates) (Arya et al., 2018) may suggest a substitution of methods in the Indian population in the latter part of the study period.

Suicide by hanging is known to be difficult to restrict given that ligature material and ligature points are commonly available (Gunnell et al., 2005). However, the identification of commonly used ligature points, such as ceiling fans (Supraja et al., 2016) (particularly prevalent among lower income households) (Letschert et al., 2009) may be a target for current prevention initiatives; if ceiling fans are commonly used as a ligature point, then strategies might be put in place to make them safer. For example, installing spring fitted ceiling fans that would drop if a weight over $20 \mathrm{~kg}$ is suspended on them (Mishra et al., 2019). Other prevention strategies may relate to collaborative efforts with the media to reduce the prominent portrayal of hanging as a method of suicide (Gunnell et al., 2005; Biddle et al., 2010). For example, it has been observed that hanging is over-reported in newspaper reports on suicide events, relative to its occurrence in the general population in India, often with a detailed description of how the hanging was enacted (Armstrong et al.). Evidence suggests that sensational, simplistic and graphic reporting of suicides, a style of reporting that has been observed in India (Armstrong et al., 2018), can lead to the stigmatisation of suicidal behaviour and a reduction in help seeking behaviour while also encouraging imitation acts (Gunnell and Lewis, 2005; Pirkis et al., 2006; Patel et al., 2012; Niederkrotenthaler et al., 2014; Zalsman et al., 2016).

As noted above, though suicide by insecticide poisoning declined over the study period, it was still three times higher in more agricultural states compared to less agricultural states (for males and females), likely related to greater accessibility of pesticides in more agricultural regions (Ajdacic-Gross et al., 2008). India has banned some class I pesticides, such as Aldicarb and Calcium Cyanide, which may explain the general reduction in suicide by pesticide poisoning over the study period (Directorate of Plant Protection, Quarantine and Storage, 2018). However, in 2015-16, India used a total of 2254 tonnes of class I pesticides accounting for $29 \%$ of total pesticides use in the country (Taneja, 2017). While a recent ban has been imposed on 7 of the 18 class I pesticides allowed in India, heavily used class I pesticides (for example Monocrotophos and Carbofuran) are yet to be banned along with other known lethal pesticides (for example Paraquat) (Directorate of Plant Protection, Quarantine and Storage, 2018). Pesticide self-poisoning is thought to be often impulsive (Eddleston et al., 2006), and bans on highly toxic products, such as WHO Class I pesticides, may lead to further declines in suicide by pesticide poisoning and possibly overall suicides.

Similar to previous studies investigating overall suicide rates in India (Patel et al., 2012; Arya et al., 2018; Dandona et al., 2018), more 
(a)
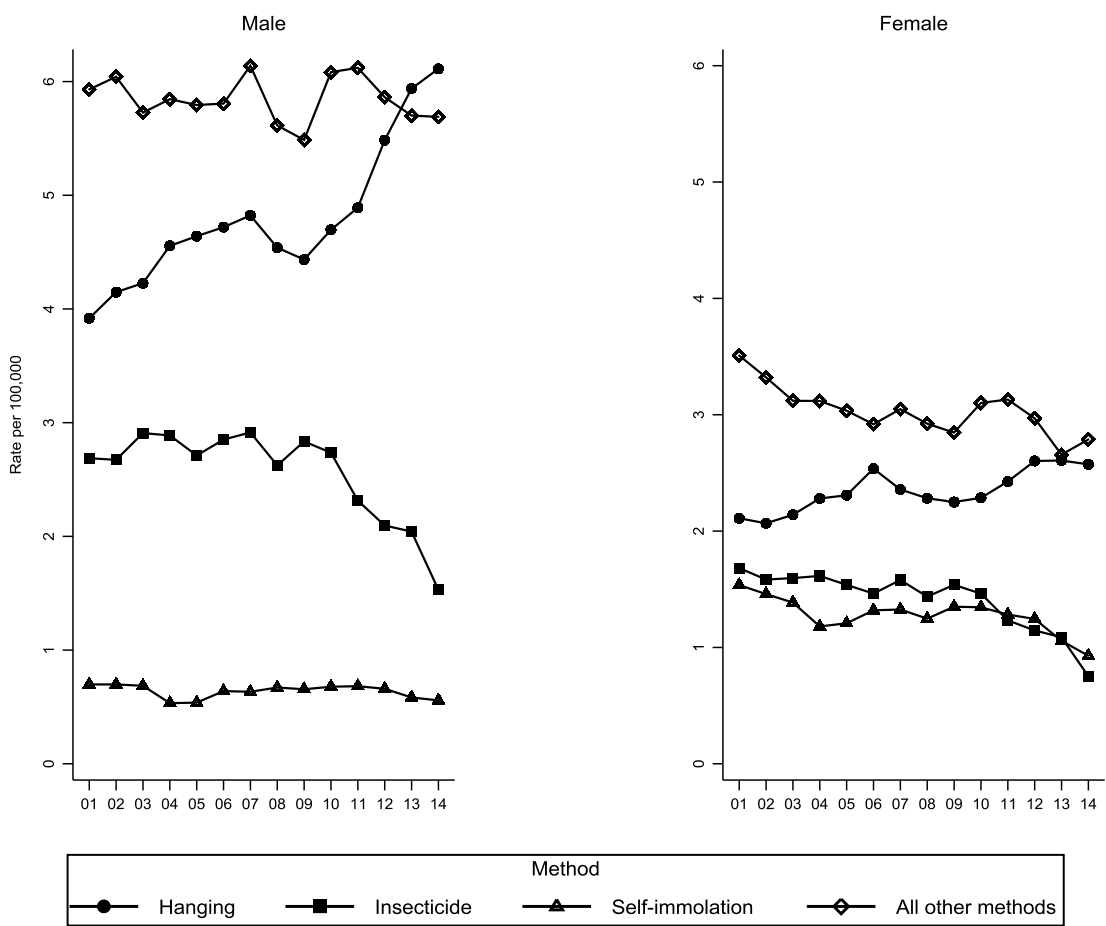

(b)
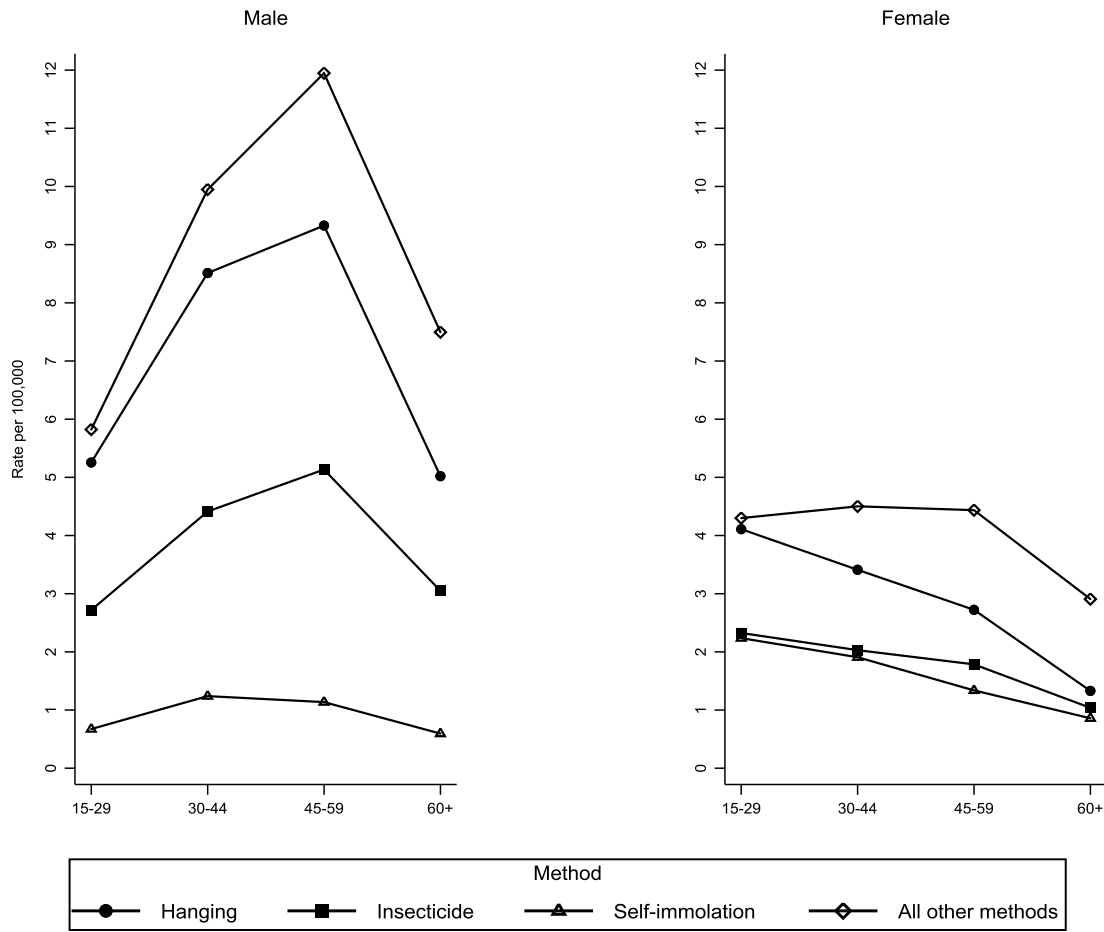

Fig. 1. Male and female method specific suicide rates, India 2001-14. (a) Direct age standardised rates; (b) Age-specific rates.

developed states had higher method specific suicide rates compared to less developed states among both sexes, perhaps associated with rapid modernization and social change in these regions, and an increasing discrepancy between expectations and reality (Mayer, 2011; Patel et al., 2012; Arya et al., 2018; Dandona et al., 2018). Rates for suicide by hanging were higher among less agricultural states compared to more 
(a)

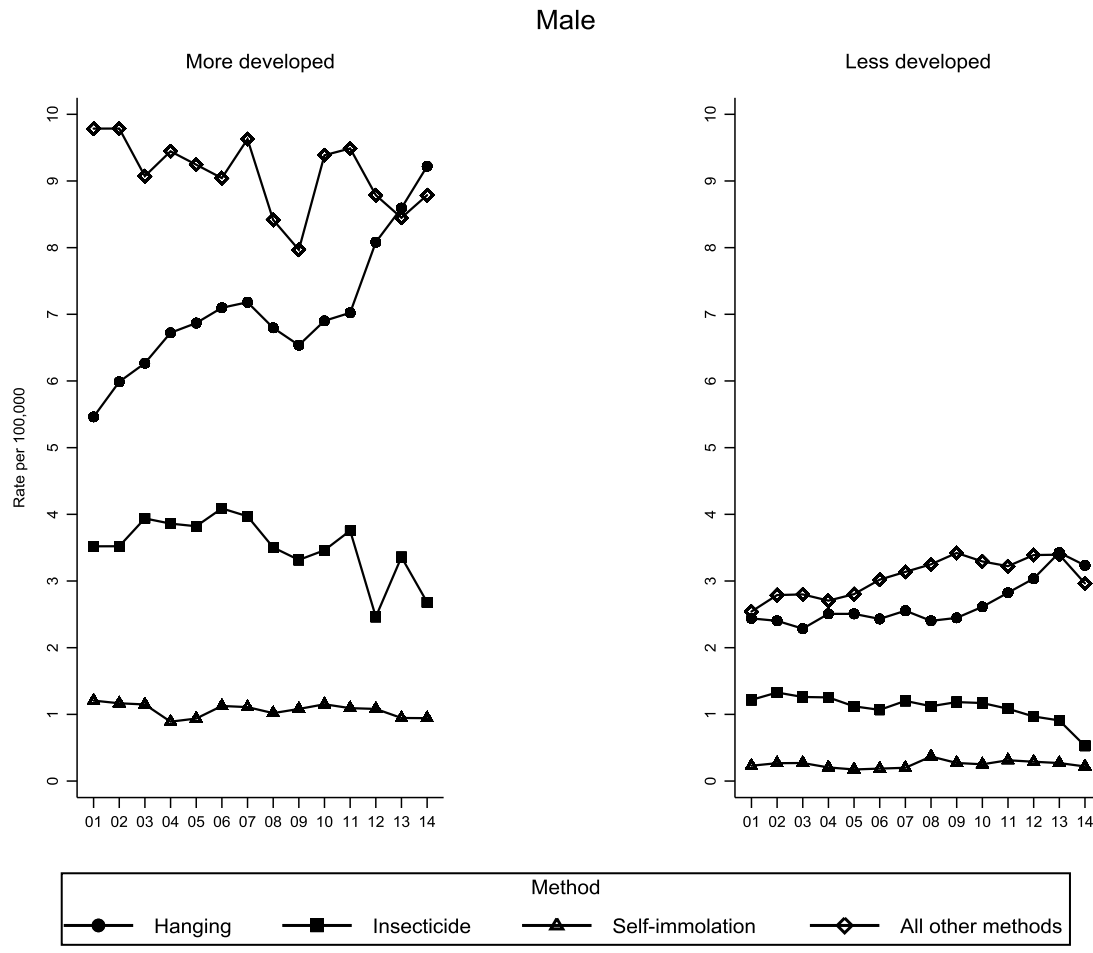

(b)

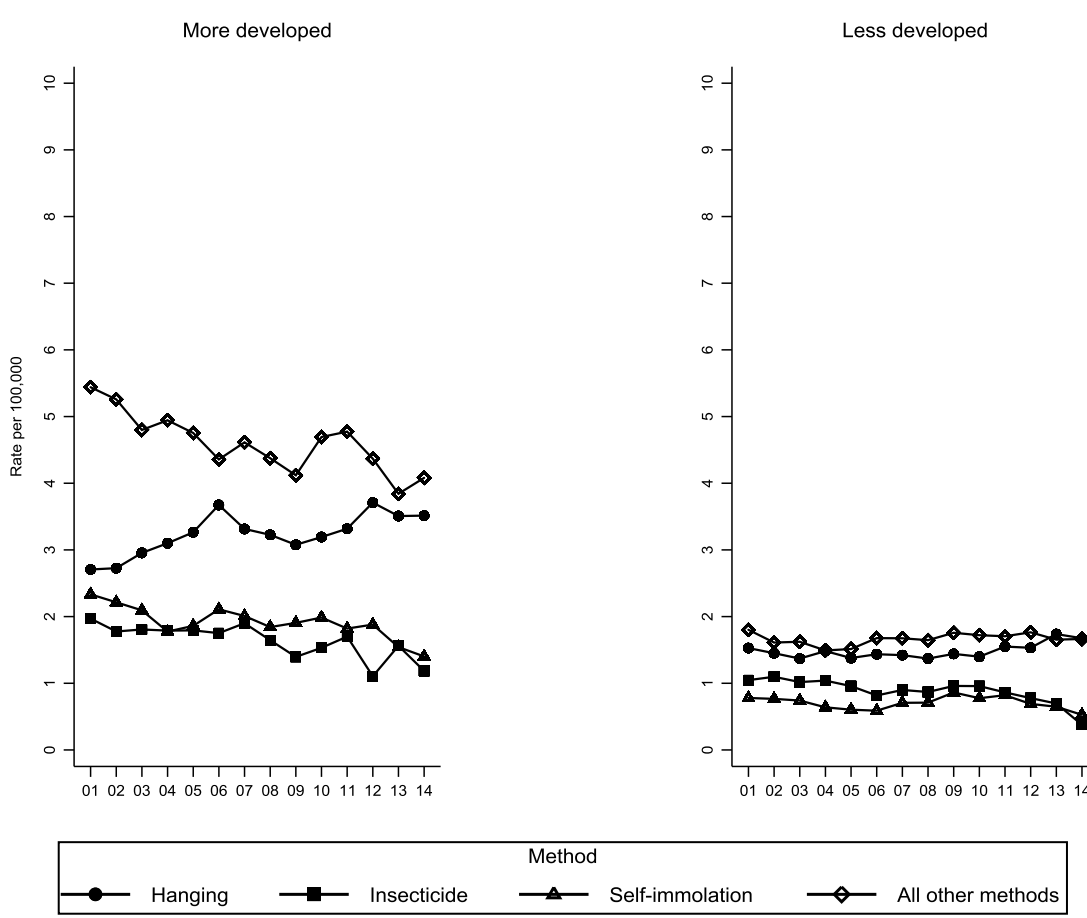

Fig. 2. Direct age-standardised method specific suicide rates by regions of economic development, India 2001-14.

agricultural states among males, while they were similar for females. Higher hanging rates among less agricultural states may be attributed to the lack of availability of other methods, such as lack of availability of pesticides (Ajdacic-Gross et al., 2008). Rates of suicide by self- immolation were also higher among more agricultural states for both sexes, which may reflect the continued use of more traditional methods of cooking including use of kerosene among agricultural regions (Bansal et al., 2013). 
(a)

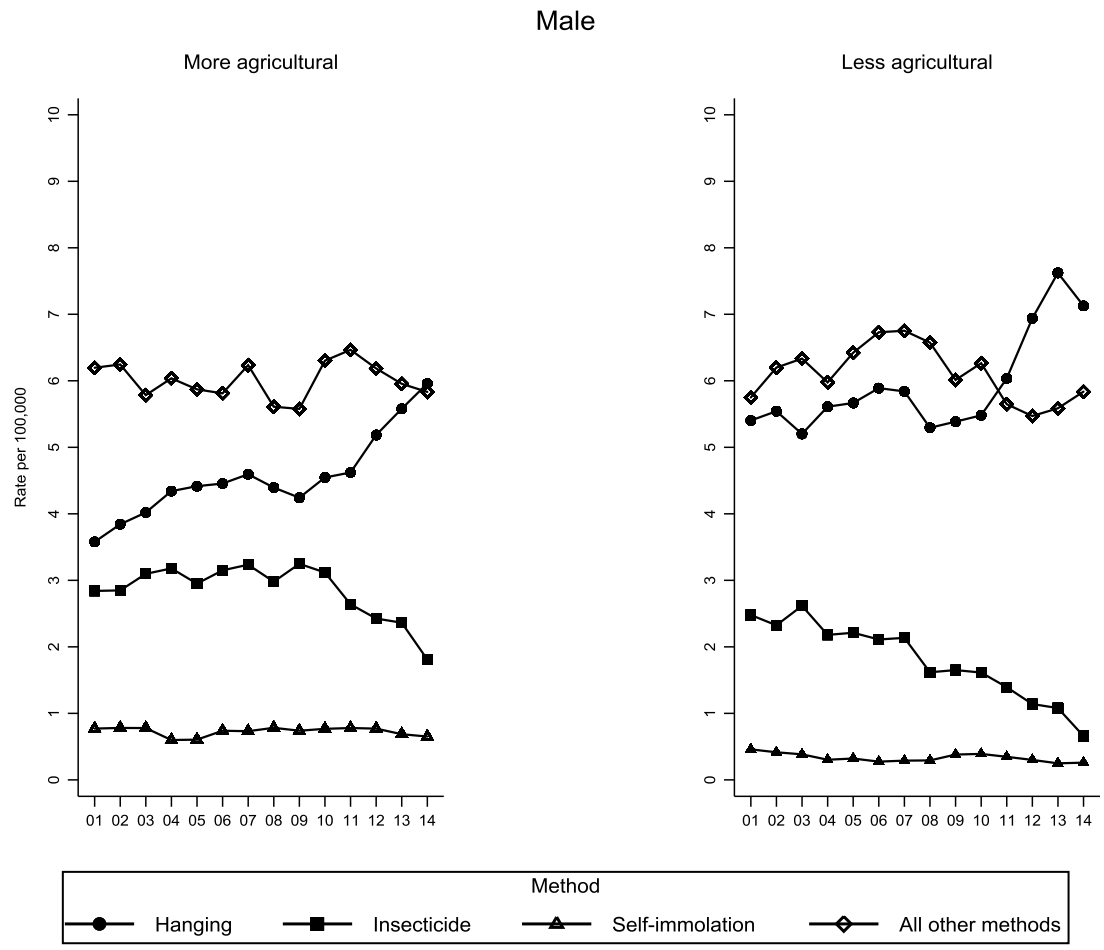

(b)

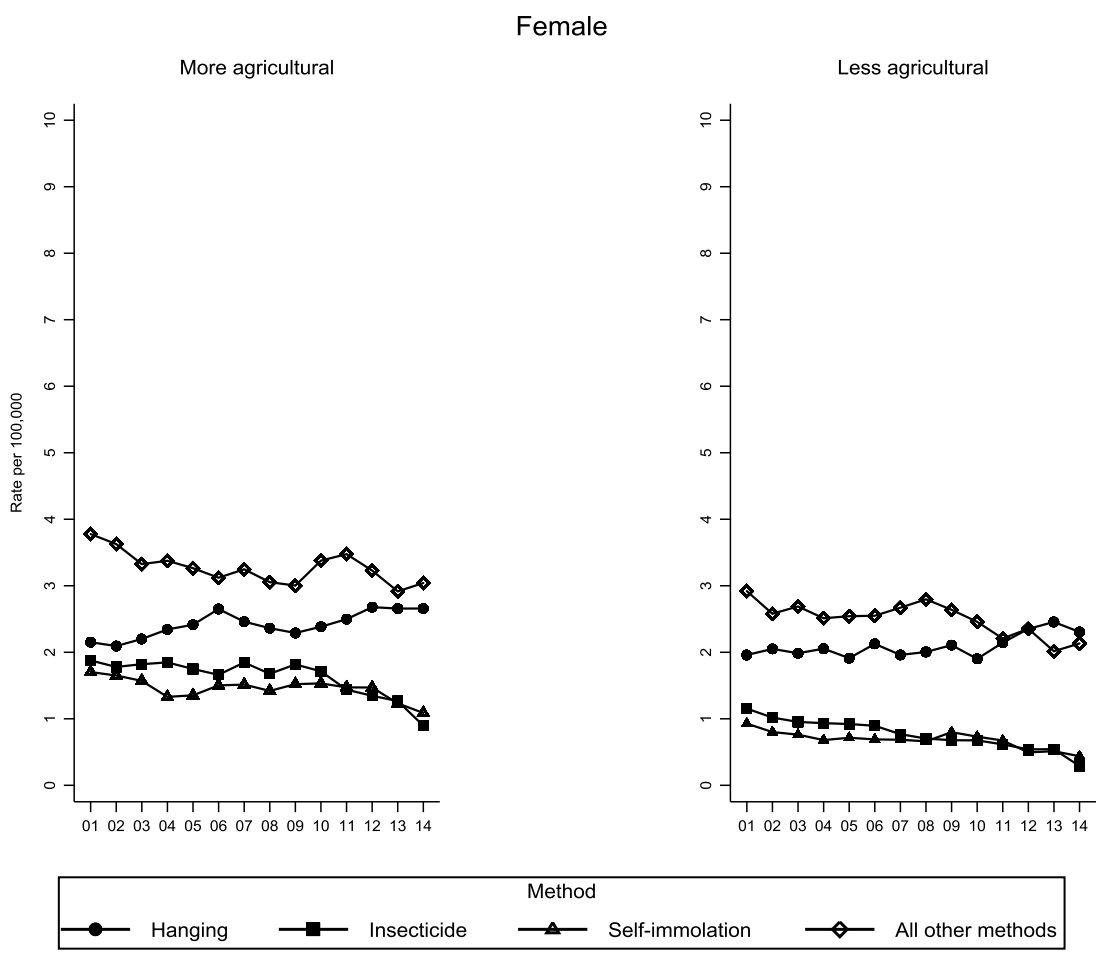

Fig. 3. Direct age-standardised method specific suicide rates by level of agriculture, India 2001-14.

Higher literacy was associated with higher suicide risk across all method categories among both sexes. Suicide rates in general are noted to be higher in populations with a higher level of literacy in India
(Arya et al., 2018). For example, southern states, which have the highest literacy rates in India have also recorded the highest suicide rates, while north Indian regions, with the lowest literacy rates in the 


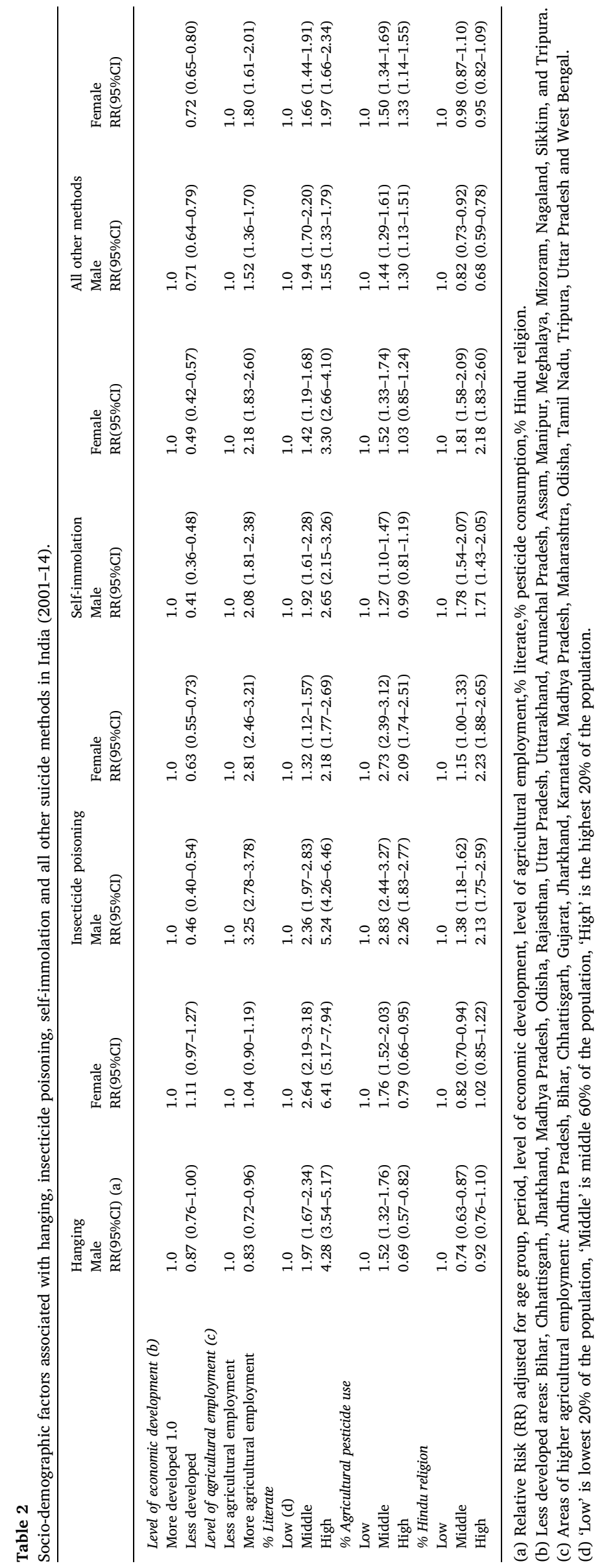


country, have recorded some of the lowest suicide rates among both sexes (Patel et al., 2012; Arya et al., 2018; Dandona et al., 2018). A higher proportion Hindu population was also associated with higher suicide risk for suicide by insecticide poisoning and self-immolation. Self-immolation among Hindus, especially among women, holds cultural significance in India (Vijayakumar, 2009). Suicide by hanging, however, showed no association between suicide risk and the proportion Hindu.

There are some methodological limitations when considering the findings of the current study. Firstly, it is acknowledged that suicide enumerated via the NCRB likely under-estimates total suicide cases in India (Patel et al., 2012; Dandona et al., 2018), given the social stigma, as well as legal ramifications associated with reporting suicidal behaviour (attempted suicide was illegal in India until 2017) (Section 309 in The Indian Penal Code; Vijaykumar, 2007; Behere et al., 2015). Specific suicide methods, such as suicide by poisoning, also may be more likely to be under-enumerated as suicidal intent is more difficult to ascertain in comparison to, for example, suicide by hanging (Gunnell et al., 2013). Furthermore, pesticide poisoning suicides might also be underestimated due to their misclassification as 'other poisoning' suicides in the NCRB data. The NCRB suicide data suggests such misclassification for the year 2015 where 'insecticide poisoning' suicides note a sharp upward trend coinciding with a sharp downward trend in 'other poisoning' suicides (Web Appendix 8). Further investigation of this potentially artefactual misclassification is required when more recent data for years post-2015 become available. However, in general, both, 'insecticide poisoning' and 'other poisoning' note a downward trend from 2001-2014. Secondly, the study derives population and covariate estimates from two census years with inter-censal years interpolated, potentially under-estimating any non-linear trends in the covariates included in analyses. Additionally, the identified socio-demographic factors were specified as ecological variables for each region (that is as a proportion of the corresponding population), which limits the attribution of associations of these characteristics to individuals residing within these regions.

Suicide by hanging is the leading method of suicide in India for both males and females, and has increased substantially in the most recent period. This has occurred in the context of declines in suicide by insecticide poisoning, and stable overall suicide rates in males and females. The prominence of media reports and fictional portrayals of suicide by hanging in India may be areas of priority for suicide prevention initiatives. Suicide by insecticide poisoning also remains an important priority for prevention, especially in more agricultural regions where accessibility to pesticides is more common, and a continuation of restricting access (through sales and import mechanisms) to hazardous pesticides is likely to be an effective prevention strategy. Suicide has emerged as an important public health issue in India, and current study findings indicate that the geographic and socio-demographic heterogeneity of suicide methods will need to be considered in future strategic responses and the prioritisation of suicide prevention activity.

\section{CRediT authorship contribution statement}

Vikas Arya: Conceptualization, Data curation, Formal analysis, Writing - original draft, Writing - review \& editing. Andrew Page: Conceptualization, Writing - review \& editing. David Gunnell: Writing - review \& editing. Rakhi Dandona: Writing - review \& editing. Haider Mannan: Writing - review \& editing. Michael Eddleston: Writing review \& editing. Gregory Armstrong: Writing - review \& editing.

\section{Acknowledgements}

None.

\section{Funding}

This work was supported by Australian Government Research Training Program Scholarship which has been awarded to Vikas Arya as part of his doctoral research.

\section{Conflict of interest}

On behalf of all authors, the corresponding author states that there is no conflict of interest.

\section{Supplementary materials}

Supplementary material associated with this article can be found, in the online version, at doi:10.1016/j.jad.2019.07.005.

\section{References}

Ajdacic-Gross, V., Weiss, M.G., Ring, M., Hepp, U., Bopp, M., Gutzwiller, F., Rössler, W., 2008. Methods of suicide: international suicide patterns derived from the WHO mortality database. Bull. World Health Organ. 86, 726-732 pp.

Ambade, V.N., Godbole, H.V., Kukde, H.G., 2007. Suicidal and homicidal deaths: a comparative and circumstantial approach. J. Forensic Leg. Med. 14 (5), 253-260 pp.

Armstrong G, Vijayakumar L, Pirkis J, Jayaseelan M, Cherian A, Sørensen JB, Arya V, Niederkrotenthaler T. Mass media representation of suicide deaths in India: an epidemiological comparison with suicide deaths in the population. Under review.

Armstrong, G., Vijayakumar, L., 2018. Suicide in India: a complex public health tragedy in need of a plan. Lancet Public Health 3 (10), e459-e460 pp.

Armstrong, G., Vijayakumar, L., Niederkrotenthaler, T., Jayaseelan, M., Kannan, R., Pirkis, J., Jorm, A.F., 2018. Assessing the quality of media reporting of suicide news in India against World Health Organization guidelines: a content analysis study of nine major newspapers in Tamil Nadu. Austr. N. Zeal. J. Psychiatry 52 (9), 856-863 pp.

Arya, V., Page, A., River, J., Armstrong, G., Mayer, P., 2018. Trends and socio-economic determinants of suicide in India: 2001-2013. Soc. Psychiatry Psychiatr. Epidemiol. 53 (3), 269-278 pp.

Bansal, M., Saini, R.P., Khatod, D.K., 2013. Development of cooking sector in rural areas in India-a review. Renew. Sustain. Energy Rev. 17, 44-53 pp.

Beautrais, A.L., Fergusson, D.M., Horwood, L.J., 2006. Firearms legislation and reductions in firearm-related suicide deaths in New Zealand. Austr. N. Zeal. J. Psychiatry 40 (3), 253-259 pp.

Behere, P.B., Rao, T.S., Mulmule, A.N., 2015. Decriminalization of attempted suicide law: journey of fifteen decades. Indian J. Psychiatry 57 (2), 122 p.

Biddle, L., Donovan, J., Owen-Smith, A., Potokar, J., Longson, D., Hawton, K., Kapur, N., Gunnell, D., 2010. Factors influencing the decision to use hanging as a method of suicide: qualitative study. Brit. J. Psychiatry 197 (4), 320-325 pp.

Census of India, 2001. Registrar General of India, Ministry of Home Affairs, Government of India. http://www.censusindia.gov.in/DigitalLibrary/TablesSeries2001.aspx (accessed 20 November 2018)

Census of India, 2011. Registrar General of India, Ministry of Home Affairs, Government of India. http://www.censusindia.gov.in/2011census/C-series/C-14.html (accessed 20 November 2018).

Chen, Y.Y., Wu, K.C.C., Wang, Y., Yip, P.S., 2016. Suicide prevention through restricting access to suicide means and hotspots. In: O'Connor, R.C., Pirkis, J. (Eds.), The International Handbook of Suicide Prevention. WILEY Blackwell, Hoboken, pp. 609-636 pp.

Dandona, R., Bertozzi-Villa, A., Kumar, G.A., Dandona, L., 2016. Lessons from a decade of suicide surveillance in India: who, why and how? Int. J. Epidemiol. 46 (3), 983-993 pp.

Dandona, R., Kumar, G.A., Dhaliwal, R.S., Naghavi, M., Vos, T., Shukla, D.K., Vijayakumar, L., Gururaj, G., Thakur, J.S., Ambekar, A., Sagar, R., 2018. Gender differentials and state variations in suicide deaths in India: the global burden of disease study 1990-2016. Lancet Public Health 3 (10), e478-e489 pp.

Directorate of Plant Protection, Quarantine \& Storage, Government of India. List of Banned Pesticides in India as On 30.09.2018. http://ppqs.gov.in/divisions/cib-rc/ registered-products(accessed December 22 2018).

Eddleston, M., Karunaratne, A., Weerakoon, M., Kumarasinghe, S., Rajapakshe, M., Rezvi Sheriff, M.H., Buckley, N.A., Gunnell, D., 2006. Choice of poison for intentional selfpoisoning in rural Sri Lanka. Clin. Toxicol. 44 (3), 283-286 pp.

Gunnell, D., Bennewith, O., Hawton, K., Simkin, S., Kapur, N., 2005. The epidemiology and prevention of suicide by hanging: a systematic review. Int. J. Epidemiol. 34 (2), 433-442 pp.

Gunnell, D., Bennewith, O., Simkin, S., Cooper, J., Klineberg, E., Rodway, C., Sutton, L., Steeg, S., Wells, C., Hawton, K., Kapur, N., 2013. Time trends in coroners' use of different verdicts for possible suicides and their impact on officially reported incidence of suicide in England: 1990-2005. Psychol. Med. 43 (7), 1415-1422 pp.

Gunnell, D., Fernando, R., Hewagama, M., Priyangika, W.D.D., Konradsen, F., Eddleston, M., 2007. The impact of pesticide regulations on suicide in Sri Lanka. Int. J. Epidemiol. 36 (6), 1235-1242 pp.

Gunnell, D., Lewis, G., 2005. Studying suicide from the life course perspective: 
implications for prevention. Brit. J. Psychiatry 187 (3), 206-208 pp.

IASRI, 2013. Statewise Consumption of Pesticides (technical grade) in India. Agricultural research Data Book 2013. http://www.iasri.res.in/agridata/13data/chapter2/ db2013tb2_16.pdf (accessed 01 June 2018).

IASRI, 2016. Statewise Consumption of Pesticides (technical grade) in India. Agricultural research Data Book 2016. http://www.iasri.res.in/agridata/16data/chapter2/ db2016tb2_11.pdf (accessed 01 June 2018).

Kreitman, N., 1976. The coal gas story. United Kingdom suicide rates, 1960-71. J. Epidemiol. Commun. Health 30 (2), 86-93 pp.

Letschert, V., McNeil, M., Zhou, N., Sathaye, J., 2009. Residential and Transport Energy Use in India: Past Trend and Future Outlook (No. LBNL-1753E). Lawrence Berkeley National Lab, Berkeley, CA.

Literates and Literacy Rates by Sex - Census 2001 and 2011, 2018. https://data.gov.in/ resources/literates-and-literacy-rates-sex-census-2001-and-2011(accessed 02 April 2018).

Mann, J.J., Apter, A., Bertolote, J., Beautrais, A., Currier, D., Haas, A., Hegerl, U., Lonnqvist, J., Malone, K., Marusic, A., Mehlum, L., 2005. Suicide prevention strategies: a systematic review. JAMA 294 (16), 2064-2074 pp.

Mayer, P., 2011. Suicide and Society in India. Routledge, New York.

Mishra, A, Gunji, B, Deepak, BB, 2019. A new safety design of the ceiling fan to avoid suicidal cases. Research into Design for a Connected World 2019. Springer, Singapore, pp. 715-724 pp.

Mitchell, M.N., 2012. Interpreting and Visualizing Regression Models Using Stata (No. 005.369 M58.). Stata Press, College Station, TX.

National Crime Records Bureau, 2014. Accidental Deaths and Suicides in India. Government of India, New Delhi. http://ncrb.gov.in/StatPublications/ADSI ADSI2014/adsi-2014\%20full\%20report.pdf (accessed 10 July 2018).

Niederkrotenthaler, T., Reidenberg, D.J., Till, B., Gould, M.S., 2014. Increasing helpseeking and referrals for individuals at risk for suicide by decreasing stigma: the role of mass media. Am. J. Prev. Med. 47 (3), S235-S243 pp.

Oliver, R.G., Hetzel, B.S., 1972. Rise and fall of suicide rates in Australia: relation to sedative availability. Med. J. Austr. 2 (17), 919-923 pp.

Page, A., Liu, S., Gunnell, D., Astell-Burt, T., Feng, X., Wang, L., Zhou, M., 2017. Suicide by pesticide poisoning remains a priority for suicide prevention in China: analysis of national mortality trends 2006-2013. J. Affect. Disord. 208, 418-423 pp.

Patel, V., Ramasundarahettige, C., Vijayakumar, L., Thakur, J.S., Gajalakshmi, V., Gururaj, G., Suraweera, W., Jha, P., Million Death Study Collaborators, 2012. Suicide mortality in India: a nationally representative survey. Lancet 379 (9834), 2343-2351 pp.

Pirkis, J.E., Burgess, P.M., Francis, C., Blood, R.W., Jolley, D.J., 2006. The relationship between media reporting of suicide and actual suicide in Australia. Soc. Sci. Med. 62 (11), 2874-2886 pp.

Population by Major Religious Communities (Census 2001). https://data.gov.in/ resources/population-major-religious-communities-census-2001(accessed 02 April 2018).

Religion Census, 2011. Census of India, 2011. http://www.census2011.co.in/religion. php (accessed 02 April 2018).

Sauvaget, C., Ramadas, K., Fayette, J.M., Thomas, G., Thara, S., Sankaranarayanan, R., 2009. Completed suicide in adults of rural Kerala: rates and determinants. Natl. Med. J. India 22 (5), $228 \mathrm{p}$.

Section 309 in the Indian Penal Code. Indiankanoon.org.http://indiankanoon.org/doc/ 1501595/(accessed 20 January 2019).

Spittal, M.J., Pirkis, J., Miller, M., Studdert, D.M., 2012. Declines in the lethality of suicide attempts explain the decline in suicide deaths in Australia. PLoS ONE 7 (9), e44565 p.

Supraja, T.A., Thennarasu, K., Satyanarayana, V.A., Seena, T.K., Desai, G., Jangam, K.V., Chandra, P.S., 2016. Suicidality in early pregnancy among antepartum mothers in urban India. Arch. Womens Ment. Health 19 (6), 1101-1108 pp.

Taneja, S., 2017. Why India continues to use lethal pesticides. Downtoearth.org.in. https://www.downtoearth.org.in/news/agriculture/vidarbha-s-toxic-trail-59173(accessed December 22 2018).

Thakur, U., 1963. The History of Suicide in India: An Introduction. Munshi Ram Manohar Lal, Delhi.

Vijayakumar, L., 2009. Hindu religion and suicide in india. In: Wasserman, D., Wasserman, C. (Eds.), Oxford Textbook of Suicidology and Suicide Prevention. OUP, Oxford, pp. 19-25 pp.

Vijayakumar, L., Nagaraj, K., Pirkis, J., Whiteford, H., 2005. Suicide in developing countries (1) frequency, distribution, and association with socioeconomic indicators. Crisis 26 (3), 104-111 pp.

Vijaykumar, L., 2007. Suicide and its prevention: the urgent need in india. Indian J. Psychiatry 49 (2), $81 \mathrm{p}$.

World Health Organization, 2011. Suicide Rates per 100,000 by Country, Year, and Sex. WHO, Geneva.

World Health Organization, 2014. Preventing suicide: A global Imperative. WHO, Geneva.

Yip, P.S., Caine, E., Yousuf, S., Chang, S.S., Wu, K.C.C., Chen, Y.Y., 2012. Means restriction for suicide prevention. Lancet 379 (9834), 2393-2399 pp.

Zalsman, G., Hawton, K., Wasserman, D., van Heeringen, K., Arensman, E., Sarchiapone, M., Carli, V., Höschl, C., Barzilay, R., Balazs, J., Purebl, G., 2016. Suicide prevention strategies revisited: 10-year systematic review. Lancet Psychiatry 3 (7), 646-659 pp. 


\section{University Library}

\section{- M I N E R VA \\ A gateway to Melbourne's research publications}

Minerva Access is the Institutional Repository of The University of Melbourne

Author/s:

Arya, V;Page, A;Gunnell, D;Dandona, R;Mannan, HA;Eddleston, M;Armstrong, G

Title:

Suicide by hanging is a priority for suicide prevention: method specific suicide in India (2001-2014)

Date:

2019-10-01

\section{Citation:}

Arya, V., Page, A., Gunnell, D., Dandona, R., Mannan, H. A., Eddleston, M. \& Armstrong, G. (2019). Suicide by hanging is a priority for suicide prevention: method specific suicide in India (2001-2014). JOURNAL OF AFFECTIVE DISORDERS, 257, pp.1-9. https:// doi.org/10.1016/j.jad.2019.07.005.

Persistent Link:

http://hdl.handle.net/11343/268056 